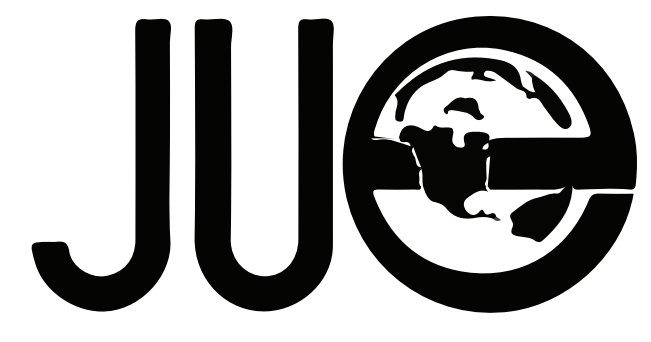

The Journal for Undergraduate Ethnography

Volume 6 | Issue 2

ISSN 2369-8721

\title{
Retention in Kindergarten: A Case Study of Teacher Perceptions and Practices
}

\section{Haley Wofford}

Presbyterian College, hewofford@presby.edu

\section{ABSTRACT}

he educational practice of retention - holding a student back to repeat a year - is a strategy used in many schools in the USA to improve outcomes for students, even at the kindergarten level. Research findings on retention in kindergarten are inconsistent

with regards to reasons for and benefits of retaining students. Examining the issue using a case study can provide valuable insight into how retention decisions are made and what the perceived benefits are. This study draws on data from a survey, an interview and 40 hours of classroom observations to explore one teacher's views of kindergarten retention and the interventions she used to help students at risk of retention, as well as the type of feedback she gave at-risk students in the classroom. It was found that the teacher emphasized motivating and involving at-risk students and working with them one-on-one. Overall, though, she felt that parents working with their children at home could make the difference in whether a student was retained or not. Since three of the five students the teacher identified as being at risk for retention were Hispanic, and research indicates that the expectations for this type of parental involvement may not be familiar to Hispanic families, I conclude that teachers should explicitly communicate and explain these expectations to all parents. 
Historically, retention - holding a student back to repeat a year has been used in some education systems as a form of remediation for students who fail to achieve specific academic targets (Frey 2005). A teacher's perception of retention shapes their concept of what academic accomplishment is (and vice versa). If a teacher does not believe that retention is good for students, he or she will implement many interventions to try and prevent students from being retained. If a teacher believes that retention is good for students, he or she may not implement any interventions that will help students in their development and academic achievement. Perceptions of retention can differ widely, as can retention policies, which in the USA may be based on the views of the principal, the school district, and sometimes the state (Range et al. 2012). Retention policies and teachers' perceptions of retention can affect students' likelihood of being retained and can influence students' academic future (Goldstein, Eastwood, and Behuniak 2013; Okpala 2007).

Retention can be used in the very first year of elementary school, kindergarten, during which children are taught such skills as letter-sound recognition sight words, concepts of print, basic reading strategies, as well as number recognition and 1-digit addition. Such academic achievements and various other developmental levels are evaluated when determining whether a kindergarten student is ready to be promoted to first grade. Kindergarten students are typically assessed on cognitive, social, and emotional developmental levels (Ray and Smith 2010). These levels are used as predictors of the student's knowledge and development, and assessments in these domains play a role in decision about whether to retain a student or not. Researchers have found that many teachers and principals support the use of retention, especially in lower grades such as kindergarten (Guanglei and Raudenbush 2006; Range et al. 2012). However, research findings on the effectiveness of retention are contradictory, some indicating that retention has no effect on academic success and other findings indicating that it does (Frey 2005; Guanglei and Radenbush
2006). The individual teacher's views on retention can shape the interventions he or she uses. They can also play a role in how students' academic success is perceived in the classroom (Okpala 2007). Even though there is little agreement on the effects of retention on students, studies have found that certain students are more likely to be retained than others. For example, Goldstein et al. (2013) found that teachers' perceptions of students based upon their ethnic and social background were predictors of kindergarten retention.

The purpose of this study was to gain a deeper understanding about one teacher's perceptions of retention in kindergarten, the feedback she gave students she felt were at risk of being retained, and the interventions she used with these students (to whom I refer for the remainder of this paper as "at-risk" students). I administered a survey and conducted an interview with the teacher, and performed classroom observations to collect data to answer the three questions guiding my research: (a) What are the teacher's views on retention? (b) What type of feedback is given to atrisk students? and (c) What additional supports and interventions does the teacher provide for at-risk students?

\section{Literature Review: Retention and its predictors}

Much research on retention in kindergarten and its effects has been conducted throughout the years. Researchers have studied the perceptions of teachers on retention, whether retention is used as a form of intervention, and the long-term effects of retention on students who were retained. Although some research has indicated an association between lack of parental involvement and students' increased risk of being retained, these studies have typically focused on retention in later grades (e.g., LaRocque, Kleiman, and Darling 2011; Machen, Wilson, and Notar 2005). 


\section{Teachers' Perceptions of Retention}

One important component of whether students will be retained is teachers' and principals' attitudes toward retention. If educators feel that retention is beneficial, they are likely to recommend retention as intervention for struggling students. Range et al. (2012) administered a survey to identify the attitudes toward retention of 206 primary grade teachers and 39 elementary principals across the USA. They found that $64 \%$ teachers and $68 \%$ of p rincipals said that they would use retention as an intervention for students who were struggling academically. This research indicates that the majority of teachers and principals in the USA favor the use of retention for young children. Similarly, Okpala (2007) surveyed randomly selected kindergarten teachers in public elementary schools in one school district in North Carolina about the use of retention. She found that the majority of teachers believed that retention was a necessary intervention for struggling students. These findings may not be generalizable to other states given that all participants were teachers in North Carolina. Overall, though, these studies suggest that when students are struggling academically, most educators favor retaining students in early grades such as kindergarten.

\section{Predictors of Retention}

Other research reveals that certain student characteristics increase the probability of students being retained. Even though retention is used for struggling students, some types of students still have a higher chance of being retained than others.

Goldstein et al. (2013) examined results of the Kindergarten Entrance Inventory (KEI) for 40713 kindergarten students in Connecticut to identify predictors of retention. The researchers found that teachers' perceptions of low literacy and numeracy skills were predictors of kindergarten retention. In addition, students who were male, had disabilities, and received free or reduced-price lunch were at increased risk of being retained.
Byrd and Weitzman (1994) also studied predictors of kindergarten retention, with a focus on health and social factors. The sample was 17110 children ranging in age from 7 to 17 who were included in two national surveys, the Child Health Supplement and the National Health Interview Survey. The researchers analyzed data from these surveys and compared demographic characteristics and health-related problems to percentages of grade repetition. It was found that being from low socioeconomic status (SES), single-parent or teen-parent homes, and being male were all predictors of being retained. Students who had hearing or speech impairments, low birth weight, and high cigarette smoke exposure were also more likely than other students to be retained.

In another study on the relationship between students who were retained and their demographic characteristics, Winsler et al. (2012) analyzed 14813 students' academic success throughout their first two years of school and compared it to their test scores, teacher evaluations, SES, gender, and ethnicity. They found that 500 of the students had been retained and completed a second year of kindergarten. Children who were White and children with lower language and social skills than other children were more likely to be retained.

Common findings in these studies indicate that being from a low SES family and being male increase students' chances of being retained. Students with disabilities are also at increased risk of being retained in kindergarten. In other words, children of different genders, abilities, and poverty levels do not have the same likelihood of being retained. 


\section{Retention vs. Social Promotion}

The most common alternative to retention is social promotion. This happens when a struggling student is promoted to the next grade level in order to maintain his or her social development in relation to the peer group (Frey 2005; Range et al. 2012). This option is typically chosen for students who interact appropriately with their peers but have slight academic struggles, in the hopes that they will soon catch up after being promoted.

In the 1990s, Peel (1997) conducted research to find out how widespread kindergarten retention was in North Carolina and what the effects of being promoted were on students deemed not ready for first grade. Surveys were distributed to kindergarten teachers in 555 North Carolina schools. The researcher found that there were an equal number of students who were retained and students who were promoted but the teacher felt were not ready. Overall, developmental delays and immaturity were the most common reasons teachers gave for retaining students.

Mantizicopoulas (1997) focused on the extent to which children with significant attention problems benefit from early retention. She examined outcomes for a total of 40 students, 25 of whom were retained and 15 of whom were promoted. The researcher administered SEARCH, a screening tool that is used to predict kindergarten retention and also provides a behavioral check-up list each year after kindergarten. The researcher concluded that there were no academic differences between students who were promoted and students who were retained.

Hong and Raudenbush (2006) studied schools with high retention rates to examine the effects of retention on students who were retained with many peers or few peers, and also the effect that a high school retention rate had on students who were not at risk of being retained. The researchers followed 471 retained students and 10255 promoted students, and compared the school's retention rate with the number of kindergarteners retained. They concluded that children who were retained in high retention rate schools would have performed better if promoted. However, high retention rates had no effect on students who were not at-risk. This finding indicates that even though most teachers and principals believe retention is beneficial for struggling students, this may not always be the case.

Findings from this review of research on retention indicate that in most cases, teachers and principals view retention as a necessary intervention for struggling students in the early grades. However, there is little consensus regarding criteria used in making retention decisions. Overall, students who are male, have a disability, and come from low SES homes are more likely than other students to be retained. In addition, there is also no clear evidence for how successful retention is (Hong and Raudenbush 2006; Mantizicopoulas 1997).

\section{Methods}

\section{Setting}

This study was conducted at Lincoln Elementary School in a kindergarten class for 5-year-olds. There was one teacher, Mrs. Jones, and one teacher aide in the classroom. Lincoln is located in an urban part of rural Wilkins County, South Carolina, population 66533 . There are six elementary schools, two middle schools, one high school, and one alternative school in the school district. According to the U.S. Census Bureau, 20.6\% of the Wilkins County population lives below the poverty level. The county also has a high Latino/a population. Pseudonyms for the school district, the school, the teacher, and the students are used throughout this paper to protect the privacy of participants.

I chose this setting because I spent one semester in Mrs. Jones' classroom for a practicum teaching experience as part of my undergraduate education program. I spent 30 hours in her classroom, during which time I conducted observations, did small group instruction with struggling students, and taught several 
lessons. Since Mrs. Jones had previously retained students in kindergarten, I realized that this setting would provide me with suitable data for my study. I therefore returned the following semester to do 10 more hours of focused observations.

\section{Participants}

Of the 518 students at the school, $36.5 \%$ were White, $37.8 \%$ were Hispanic, $24.9 \%$ were Black, and $0.7 \%$ were Asian. The majority of students who attended Lincoln came from low SES families. Every student in the school received lunch at no cost to the family. There were 20 students in Mrs. Jones' kindergarten classroom: nine were Hispanic, six were White, three were African American, one was Asian, and one was mixed-race. Mrs. Jones identified five of the 20 students in the classroom as being at risk of retention. One of these students was a White boy, one was a White girl, one was a Hispanic boy, and two were Hispanic girls. In other words, three of the five at-risk students were Hispanic. These th ree students came from homes where English was not the primary language spoken, and therefore received English language learner (ELL) services in school. Table 1 summarizes information about the students the teacher identified as being at risk of being retained in kindergarten.
Table 1: Student Demographic and Background Information

\begin{tabular}{|c|c|c|l|}
\hline Student & Race/Ethnicity & Gender & \multicolumn{1}{|c|}{ Background } \\
\hline Holly & White & Female & $\begin{array}{l}\text { Holly was new to the } \\
\text { school and lived with } \\
\text { her grandparents } \\
\text { because her mother } \\
\text { was “in and out" of the } \\
\text { home. She was currently } \\
\text { repeating kindergarten. }\end{array}$ \\
\hline Eric & White & Male & $\begin{array}{l}\text { Eric had severe behavior } \\
\text { problems and possible } \\
\text { ADHD. After 11 weeks } \\
\text { of school, he could not } \\
\text { recognize four letters } \\
\text { (m, t, s, a) they had been } \\
\text { working on. }\end{array}$ \\
\hline Philippe & Hispanic & Male & $\begin{array}{l}\text { Philippe was new to } \\
\text { the school. His family } \\
\text { moved from Guatemala } \\
\text { and no English was } \\
\text { spoken at home. His } \\
\text { neighbor, a child in 3rd } \\
\text { grade, worked with him } \\
\text { based on directions } \\
\text { given by the teacher. }\end{array}$ \\
\hline Martha & Hispanic & Female & $\begin{array}{l}\text { Marthas father worked } \\
\text { with her on all work } \\
\text { sent home. No English } \\
\text { was spoken at home. }\end{array}$ \\
& Hispanic & Female & $\begin{array}{l}\text { Isabella did not attend } \\
\text { school often. She may } \\
\text { have moved and trans- } \\
\text { ferred to another school. }\end{array}$ \\
\hline
\end{tabular}




\section{Data Collection}

I obtained approval for my study from Presbyterian College's Institutional Review Board (IRB). I then obtained consent from the principal of the school and the teacher of the class in which I was conducting my study. The teacher sent home parental/guardian consent forms to be signed, which I obtained for all students involved in the study.

In my junior year, I conducted my practicum experience - a required part of my Bachelor of Science curriculum - in Mrs. Jones' class, spending 30 hours in her classroom throughout one semester. During this time, I conducted classroom observations in order to learn about her teaching strategies, the way she grouped students for instruction, and how she managed behaviors in the classroom. I observed her administer formal reading assessments to gather information on students' reading levels. I was also able to observe students working independently at learning centers and receiving one-on-one assistance from the classroom aide.

During my practicum, I had many conversations with Mrs. Jones about students she thought she would be retaining at the end of the year. I was then able to do more focused observations on the ways she and the classroom aide interacted with these students and the types of supports they gave students, as well as the comments they made to them regarding their work. In this phase of the study, I created a behavior chart with the categories: "positive prompt," which referred to academic feedback the teacher gave to let students know they were on the right track; "encouraging comment," such as "that looks good," typically made in reference to academic work; "individual work," during which time the teacher or aide worked with the student on an individual basis, and "use of intervention," such as leveled reading books or providing an alternate way for the student to complete the task. These four categories represented the most common behaviors I saw the teacher and aide engaging in when interacting with students the teacher considered at risk of retention. The positive prompts and encouraging comments served as verbal reinforcement for the at-risk students, whereas the individual work and use of intervention involved the teacher providing a more intense level of instructional support for the students.

The following semester, I returned to the classroom to gain further information on Mrs. Jones' views of retention and to conduct additional observations based on the categories of behaviors and classroom interventions I had seen her implement. In order to achieve the first aim, I designed a survey containing nine statements about retention, with agreement indicated on a 4-point Likert scale. There were also two open-ended questions and one list of interventions asking the teacher to check those she considered most effective at keeping struggling students from being retained. I used Mrs. Jones' survey responses to guide me in writing 12 open-ended questions for the interview I later conducted with her, which I recorded and transcribed verbatim. I then began my focused classroom observations.

For this phase of my study, I conducted classroom observations in 120-minute periods, once a week for five weeks. I used the classroom observation chart I had created based on my analysis of previous classroom observations. I recorded the interactions between the teacher and at-risk students as well as the interventions the teacher used with these students. I noted each time the teacher gave a positive prompt, made an encouraging comment, or worked with at-risk students individually or used another type of academic intervention. I took notes when each of these things occurred in the classroom and how the student responded. I did not identify any new teacher behaviors during this phase, which meant I was able to reach the point of data saturation. 


\section{Data Analysis}

The three sources of my data were classroom observations, a teacher survey, and a teacher interview. The teacher survey gave straightforward indications of the teacher's views on the purposes and consequences of retention, the factors she considered in retaining students and the grade level she felt was most appropriate for retention. It also listed which interventions she felt were most effective at preventing students from being retained. I transcribed the interview verbatim and read over the transcript to identify overarching themes. First I coded statements with terms such as "reasons" and "parental responsibilities." I then grouped comments based on these codes into common themes.

I used the observation chart during each class observation visit to help me categorize the teacher's feedback to and interventions with the at-risk students. Interestingly, I was only able to observe two of the interventions the teacher indicated as effective in the survey: additional reading programs and direct instruction. I also made notes on the chart about the teacher's actions that I observed, which I used to interpret and see broader patterns in her behavior.

I analyzed each type of data both individually and together. I read through my observation notes in conjunction with the survey results and coded interview transcript, and analyzed the data inductively by identifying patterns in teacher behaviors and beliefs.

\section{Results}

Analyzing the three types of data helped answer my guiding research questions: (a) What are the teacher's views on retention? (b) What type of feedback is given to at-risk students? and (c) What additional supports and interventions does the teacher provide for at-risk students? The survey data and teacher interview served to answer my first question about the teacher's views on retention. I analyzed my classroom observation notes to answer my second question about the type of feedback given to atrisk students. Data from the teacher interview and my classroom observations were combined to answer the third question about additional supports and interventions. Overall, I found that Mrs. Jones felt it was better to provide additional support for students in kindergarten rather than sending students to first grade without the necessary skills. She made an extra effort to encourage the at-risk students by ensuring that they were fully involved in the class. Although the teacher and teacher aide gave the at-risk students additional support in the classroom, Mrs. Jones believed that parental involvement was the best resolution for these students. I discuss these themes in more detail in the following sections.

\section{General Views on Retention}

Mrs. Jones' responses to the survey questions indicated that she agreed with the idea that retention in kindergarten prevents future failure and provides support for non-supported students. She agreed that retention in kindergarten helped maintain school and state standards. Although she felt that retention increased parent motivation to work with their child, she did state that this was a "depends" situation, meaning that it was dependent on the parents' follow-through. However, she disagreed that retention supported communication between the teacher and student or that it motivated students to attend school. The interventions she selected as those that best prevented retention were smaller class sizes, reading programs, direct instruction, and summer school. In fact, she recommended that all English language learners (ELLs) attend summer school to improve their English. Overall, Mrs. Jones was in favor of the use of retention in kindergarten in certain situations. She believed that the effectiveness of retention depended on students' unique circumstances and their level of parental support. The interview data allowed for further probing of why students were retained, how decisions were made about retention, and how parents were involved in the process. 


\section{Reasons for Retaining Students}

Mrs. Jones believed it was important for students to get basic skills while they were in kindergarten, so that the first grade teacher did not have to reteach kindergarten skills. She explained that:

It is very important for children to get the fundamental skills that are taught in kindergarten; if they don't get those skills, they don't have anything to build on. It is very hard because I have taught first and second grade also, it is very difficult to teach first and second grade skills and have to teach kindergarten skills also. You just can't do it.

Retention was thus one option to prepare children for first grade and avoid a higher-grade level teacher having to teach not only their specific content, but also the previous grade level's skills and content.

\section{Factors Considered in Retention Decisions}

Mrs. Jones indicated that students who were not making the expected level of progress in kindergarten may need to be retained. However, she specified that retention was only effective for students who had shown some progress and just needed another year to mature, not those who were not severely struggling. When students were severely struggling, she felt that getting "more of the same" was not helpful. However, she did not offer an alternative solution to retaining these students. Although Mrs. Jones used assessments such as DRA scores (reading), MAP scores (language arts and math), and writing samples in making retention decisions, she emphasized that she looked at the student as a whole and the progress they had made throughout the year. When clarifying her basis for retaining children, she divulged: "I don't really base it on a test; I base it more on what I see with the child." She also considered whether or not parents spent time working with the student at home, as she felt that having this personal attention was very beneficial to the child. She reflected on the situation by saying: "I think our greatest strength is teaching the parents how to help their children...if I can get the parent in and I can teach them, a lot of times that does make a huge difference."

In addition to students with parents who did not work with them on school work, the teacher shared that students in families where English was not the first language or was not spoken at all were at risk of being retained. It is important to note that three of the five students the teacher identified as being at risk for retention came from Hispanic families where parents may have different experiences and expectations of their role vis-à-vis school. Specifically, they may not be aware of the expectation to work with their children on school subjects. In research by Valdés (1996), it was found that parents from Mexico saw American schools as unfamiliar places, little like the schools they had experienced in Mexico. These parents experienced a mismatch between what they thought schools and parents did and the reality of American schools.

\section{Parental Responses and Interventions}

The teacher thought that retention sometimes motivated parents to work more with their child, but many times the promises parents made were not carried out. She declared: "I think the majority of children get exactly the same thing that they got before, which is why retention does not work for a child that is severely struggling." In other words, if the student did not previously receive help at home from their family, being retained would not change this situation. However, the teacher recalled that in a few cases, the thought of their child being retained became a "wake-up call" to the parents. Because of these instances, the teacher remained hopeful that parents' motivation to work with their child would increase if they knew their child was at risk of being retained. 
When talking about the five at-risk students currently in her class, the teacher reflected: "The third child, I was hoping that it would motivate mom and dad a little more, but mom just moved him to a different district and told them that he was supposed to be in first grade and he is failing miserably in first grade. It is just a really bad situation." When discussing the other at-risk students, the teacher spoke highly of one student's father by saying: "One of them, her father works with her, she has made great strides but there is no English spoken at home. He does work with her - anything I send home he works with her." In speaking so highly of this father, she was reiterating the importance she placed on parental involvement. However, with regards to another at-risk student, Mrs. Jones remarked that the student was "tribal Guatemalan; the mother speaks no language that we can reach." In this instance, language clearly posed a barrier to the parent working with their child on school work.

\section{Feedback Given to At-Risk Students}

Drawing on my observation chart and the notes I made on it, I identified two broad patterns of teacher behavior: motivating at-risk students, and requesting involvement of at-risk students.

Throughout my observations, I recorded a large number of motivating comments from both the teacher and the teacher aide directed toward the at-risk students. For example, on one occasion, the teacher aide prompted Holly to begin her writing assignment by saying: "I can't wait to read yours, why don't you go ahead and get started?" In another instance, Martha was erasing her sentences over and over again and when the teacher aide noticed what she was doing, she motivated her with the following comment: "I don't know why you are erasing your work, you are a good writer." When the teacher circulated the room or worked with the at-risk students individually, she often praised them with comments such as: "Good job!" and "Great work!" One time when Eric refused to begin his work, the teacher encouraged him by talking about how much fun it would be to write about things they just learned. The teacher and teacher aide tended to focus most of their encouraging statements on the at-risk students.

During whole group instruction, both the teacher and the teacher aide often requested involvement from the at-risk students, calling on them to participate in class discussions or to help with an activity during the morning meeting. For example, the teacher aide called on Holly to be the calendar helper, which required her to place the day of the week and the number in the correct grid in front of the whole class. Another example occurred when the teacher called on Eric to help begin the class in counting. This activity involved Eric counting alone for numbers one through ten and then the rest of the class joining in. During a class discussion, the teacher called on Martha to tell the rest of the class about something she was thankful for, which spurred her to participate in the discussion. The teacher and the teacher aide asked the atrisk students to lead or participate in class activities more often than the other students.

\section{Additional Supports and Interventions for At-Risk Students}

I answered my third guiding question about additional supports and interventions provided by the teacher for at-risk students by combining my three sources of data. My analysis allowed me to group various forms of support and intervention into two broader thematic categories: teaching parents, and working one-on-one with students.

\section{Teaching Parents}

When I asked the teacher during the interview what she felt was the best intervention to use with at-risk students, she said she liked to meet with the parents and teach them how to help their child at home. In some instances, the teacher was able to persuade older siblings to help teach their younger siblings. In the case of Philippe, the teacher went over the work with a third-grade 
The teacher explained that it was helpful when the

parent could work with their child on a one-on-one basis, stating: "I have found the greatest intervention that works the most is when I can sit down with the parent and I can teach the parent how to help the child at home....we start off with our ABC book, we teach their parents how to use the ABC book." The school had recently hosted a particularly successful parenting night:

"[Parents] received a package with an $\mathrm{ABC}$ book, things to count, they received several games to play, they also received a cookie tin that had magnetic letters on it and showed them things to do with it. So that night went really well and we hope to do that every year."

Mrs. Jones reported that everything that was done in the classroom was also taught to any parents who were willing to get involved by coming to the school, and it was expected that parents would teach the material to their child. The teacher understood that she needed to teach the parents literacy concepts so they would know how to help their child with early literacy skills. She did this by not only sending items home but by asking the parents to come in to school so she could show them how to use books and other materials. Mrs. Jones seemed aware of the need to teach parents learning activities that were not strictly academic but involved games. This was particularly important for the at-risk students for whom English was not the primary language spoken at home.

\section{Working One-on-One with Students}

The teacher aide often pulled students aside one by one and asked them to recite the $\mathrm{ABC}$ book to her. During one of my observations, she pulled the at-risk students aside and had them play games with math flashcards; however, during most of my observations the class worked on literacy activities. Small group and one-on-one work with the teacher and teacher aide were the only types of academic interventions I observed in the classroom. At the beginning of each class, the teacher would read aloud a story to the whole class. After reading the story, the teacher led a discussion around the theme of the story. Following the discussion, the teacher would work with each of the at-risk students while the rest of the class engaged in independent writing based on a writing prompt. The at-risk students were given the same assignments as the other students in the class, but received more scaffolded instruction from the teacher, including support in the form of positive prompts and encouraging comments. The other students in the classroom worked on their own and were instructed to go to the teacher aide for help if they had questions. I did not observe the teacher spending much time with the other students during independent work time; her main focus during these literacy activities was working with the at-risk students.

\section{Discussion and conclusion}

Through the 40 hours I spent in Mrs. Jones' classroom, I learned that retention in kindergarten was a common practice she used to address the needs of students and classroom teachers. Mrs. Jones thought retention was necessary to prevent teachers in first grade from having to reteach kindergarten skills. She was aware of who the at-risk students in the classroom were and focused extra attention on them. Both she and the teacher aide made a conscious effort to involve these students in whole class activities. They also made many encouraging comments to motivate these students to persevere with their work. During literacy activities, Mrs. Jones focused exclusively on the at-risk students, working with them individually while the other students worked 
on independent work. Although the teacher devoted extra attention to the at-risk students, she felt that this would not be enough to prevent these students from being retained.

The most significant finding from my research was the emphasis the teacher placed on parental involvement with academic goals. Regardless of the extra time spent working with the at-risk students on an individual basis, Mrs. Jones believed the most effective intervention involved meeting with parents and teaching them skills to work on with their children at home. She did not see this as the only intervention to prevent retention, but certainly as the best intervention. Throughout the interview, Mrs. Jones voiced her opinion that the greatest intervention for at-risk students was parents' willingness and ability to teach their children at home.

That said, this emphasis on parents teaching their children at home may be unfamiliar to many parents, particularly those from cultures where this is not the practice or expectation, perhaps because parents think their children should be learning these things at school. In some Hispanic cultures, families see the classroom teacher as the person who is qualified to teach their children correctly. They focus their in-home education on other knowledge and skills rather than school-based subjects. For example, Valdés (1996) found that when children arrived in kindergarten, the skills their mothers had taught them "did not prepare them for the world of school" (p. 141). Mothers had taught their children to be respectful and how to behave. They did not know that in the USA it was expected that they also would have taught their children colors, letters, and numbers before they reached kindergarten. The mothers thought that these were things their children would learn in school. Valdés (1996) also found that students' lack of academic preparation for kindergarten was misinterpreted by teachers as reflecting parents' lack of interest in education.
Mrs. Jones' expectations of parental involvement are not unusual. Most teachers in the USA, particularly in the early grades, expect a high level of involvement from family members. However, in many schools in the USA, the only schoolwork that is sent home with the students is in English; if the parents do not read English fluently, they can hardly be expected to teach the material to their children. Three of the five students identified as being at risk of retention in this study were Hispanic and little to no English was spoken in the home. In addition, given that most children in the school came from low-SES families, there may also have been parents whose first language was English who struggled in the area of literacy. Therefore, any written instructions that the teacher sent home would have posed a barrier to parents' ability to help their children.

My findings correspond with previous research showing that teachers support the use of retention and feel that it is necessary for struggling students in early grades (Guanglei and Raudenbush 2006; Range et al. 2012). Echoing research findings by Goldstein, Eastwood, and Behuniak (2013), my results also indicated that children from ethnic minority backgrounds may face particular challenges with regards to making the expected level of progress in kindergarten.

In line with previous research findings (e.g., Okpala 2007; Range et al. 2012), my findings indicated that Mrs. Jones believed retention was beneficial to students and she was therefore likely to recommend it as an intervention for struggling students. However, she was less focused on students' academic achievement than the overall development of the child. Previous research is inconclusive regarding the effectiveness of retention (Hong and Raudenbush 2006; Mantizicopoulas 1997) and Mrs. Jones shared these mixed sentiments. On the one hand, she felt that retention was an effective intervention for struggling students, but on the other hand, she did not feel that it was effective if the parents did not provide additional help for their children at home. An 
implication that arises from the findings of this study is that teachers to should make expectations for parental involvement clear to families and to help parents realize that if their child is struggling with language and academic goals, or even just with academic goals, their child will likely not be successful in school if they do not receive additional instructional support in the home. 


\section{Acknowledgements}

This research has taught me so many valuable things that I will be able to take with me throughout my career in education. I could not have completed this research without the endless help and support of Dr. Julia Wilkins. She was my research supervisor and work non-stop to help me. I would also like to thank Mrs. Jones for allowing me to come into her classroom and conduct my research. Finally, to my family and fiancé, thank you for standing by me through it all.

\section{REFERENCES}

Byrd, Robert S., and Michael L. Weitzman. 1994. "Predictors of Early Grade Retention Among Children in The United States.” Pediatrics 93(3): 481-87.

Frey, Nancy. 2005. "Retention, Social Promotion, and Academic Redshirting: What Do We Know and Need to Know?" Remedial and Special Education 26(6): 332-46.

Goldstein, Jessica, Melissa Eastwood, and Peter Behuniak. 2014. "Can Teacher Ratings of Students' Skills at Kindergarten Entry Predict Kindergarten Retention?.” The Journal of Educational Research 107(3): 217-29.

Hong, Guanglei, and Stephen W. Raudenbush. 2006. "Evaluating Kindergarten Retention Policy." Journal of the American Statistical Association 101(475): 901-10.

LaRocque, Michelle, Ira Kleiman, and Sharon M. Darling. 2011. "Parental involvement: The missing link in school achievement.” Preventing School Failure 55(3): 115-122.

Machen, Sandra M., Janell D. Wilson, and Charles E. Notar. 2005. "Parental involvement in the classroom." Journal of Instructional Psychology 32(1): 13-17.

Mantzicopoulos, Panayota Y. 1997. "Do Certain Groups of Children Profit From Early Retention? A Follow-Up Study of Kindergartners With Attention Problems.” Psychology in the Schools 34(2): 115-127.

Okpala, Comfort O. 2007. “The Perceptions of Kindergarten Teachers on Retention.” Journal of Research in Childhood Education 21(4): 400-5.

Peel, Betty B. 1997. "Research vs. Practice: Kindergarten Retention and Student Readiness for First Grade." Reading Improvement 34(4): 146-53.

Range, Bret G., John Pijanowski, Carleton R. Holt, and Suzie Young. 2012. “The Perceptions of Primary Grade Teachers and Elementary Principals about the Effectiveness of Grade-Level Retention." Professional Educator 36(1): 1-16.

Ray, Katherine, and Maureen C. Smith. 2010. “The Kindergarten Child: What Teachers and Administrators Need to Know to Promote Academic Success in All Children." Early Childhood Education Journal 38(1): 5-18.

Valdés, Guadalupe. 1996. Con Respeto: Bridging the Distances Between Culturally Diverse Families and Schools. New York: Teachers College Press.

Winsler, Adam, Lindsey A. Hutchison, Jessica J. De Feyter, Louis Manfra, Charles Bleiker, Suzanne C. Hartman, and Jerome Levitt. 2012. "Child, Family, and Childcare Predictors of Delayed School Entry and Kindergarten Retention among Linguistically and Ethnically Diverse Children." Developmental Psychology 48: 1299-1314.

This work is licensed under a Creative Commons Attribution-NonCommercial NoDerivs 4.0 International License. 